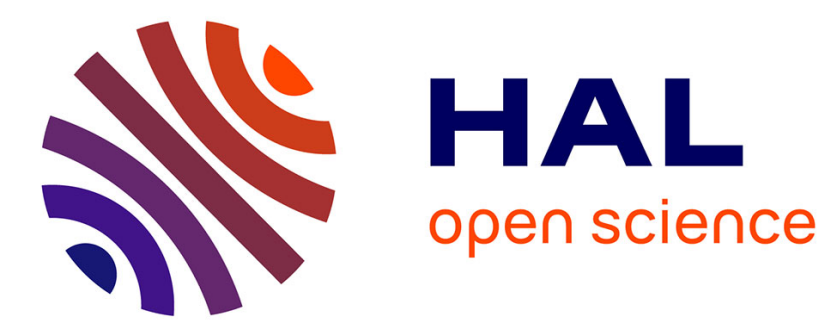

\title{
IV. Politiques culturelles territoriales : dernier inventaire avant décentralisation?
}

Emmanuel Négrier

\section{To cite this version:}

Emmanuel Négrier. IV. Politiques culturelles territoriales: dernier inventaire avant décentralisation?. Annuaire des collectivités locales , 2003, Les services publics locaux, 23, pp.47-70. 10.3406/coloc.2003.1480 . hal-01442355v2

\section{HAL Id: hal-01442355 \\ https://hal.science/hal-01442355v2}

Submitted on 28 Apr 2020

HAL is a multi-disciplinary open access archive for the deposit and dissemination of scientific research documents, whether they are published or not. The documents may come from teaching and research institutions in France or abroad, or from public or private research centers.
L'archive ouverte pluridisciplinaire HAL, est destinée au dépôt et à la diffusion de documents scientifiques de niveau recherche, publiés ou non, émanant des établissements d'enseignement et de recherche français ou étrangers, des laboratoires publics ou privés.

\section{(ㅇ)(1) $\$$}

Distributed under a Creative Commons Attribution - NonCommercial - NoDerivatives 44.0 


\section{Politiques culturelles territoriales : dernier inventaire avant} décentralisation?

Mr Emmanuel Négrier

\section{Citer ce document / Cite this document :}

Négrier Emmanuel. IV. Politiques culturelles territoriales : dernier inventaire avant décentralisation ?. In: Annuaire des collectivités locales. Tome 23, 2003. Les services publics locaux. pp. 47-70;

doi : https://doi.org/10.3406/coloc.2003.1480

https://www.persee.fr/doc/coloc_0291-4700_2003_num_23_1_1480

Fichier pdf généré le 18/05/2018 


\section{POLITIQUeS CULTURELles TERRITORIALES : DERNIER INVENTAIRE AVANT DÉCENTRALISATION ?}

\section{Emmanuel NÉGRIER}

La politique culturelle connaît-elle en France un tournant ? Plusieurs phénomènes, et pas tous récents, signalent que l'édifice progressivement mis en place depuis plus de quarante ans ${ }^{1}$ présente quelques lézardes. Du côté des pratiques culturelles, les déceptions statistiques ont accompagné, depuis vingt ans, l'implacable rigueur des analyses sociologiques ${ }^{2}$. Du côté des logiques économiques, l'exception culturelle apparaît écornée chaque jour par le poids grandissant des stratégies transnationales et des équilibres commerciaux mondiaux ${ }^{3}$. Philosophiquement, l'équation jadis lumineuse culture-démocratie s'obscurcit à l'aune des contempteurs de la culture de masse ${ }^{4}$. Financièrement, la courbe ascendante des soutiens publics présente, depuis sept ans, des irrégularités nouvelles du côté de l'État comme des pouvoirs locaux. Au plan territorial, l'émergence de nouveaux enjeux intercommunaux révèle au grand jour l'hétérogénéité des convictions locales à l'égard d'une politique cultu-

1. Voir V. Dubors, La Politique culturelle, Paris, Belin, 1999.

2. Voir P. POIRRIER, L'État et la culture en France au XXe siècle, Paris, LGF, 2000 ; P. MouliNIER, Les Politiques publiques de la culture en France, Paris, PUF, 1999 ; P. URFALINo, L'Invention de la politique culturelle, Paris, La Documentation française, 1996 ; O. DonNAT, Les Français face à la culture. De l'exclusion à l'éclectisme, Paris, La Documentation française, 1994.

3. Voir J. FARCHY, La Fin de l'exception culturelle?, Paris, CNRS Éditions, 1999.

4. P. Lebrun-CoRdier, « D'une réforme nécessaire de la politique et des institutions culturelles », Mouvements, $\mathrm{n}^{\circ}$ 17, Paris, La Découverte, automne 2001, p. 37-47; P. URFALINO, « De l'anti-impérialisme américain à la dissolution de la politique culturelle », Revue française de science politique, 1993 ; G. S.AEZ, «Vers la fin de l'État culturel ? », Revue française d'administration publique, ${ }^{\circ}$ 65, janvier-mars 1993, p. 63-72 ; F. LEXTRAIT, Friches, laboratoires, fabriques, squats, projets pluridisciplinaires... Une nouvelle époque de l'action culturelle, Rapport au secrétaire d'État au Patrimoine et à la Décentralisation culturelle, mai 2001. 
relle qui chacun pouvait croire légitime en soi. C'est dans ce cadre que se discute l'hypothèse d'une nouvelle répartition des responsabilités des pouvoirs publics, locaux et nationaux, en matière d'action culturelle. Même si, comme nous le verrons, la dimension proprement juridique de ce débat est sans doute davantage la résultante que la clef du processus, il importe d'établir sur quelles bases cette nouvelle étape pourrait s'amorcer.

L'objectif de cet article est donc de dresser un état des lieux des dynamiques territoriales actuelles des politiques culturelles. Nous analyserons la prise en charge économique et politique de l'action culturelle entre les trois niveaux de collectivité territoriale : les communes, les départements et les régions ${ }^{5}$. Dans la mesure où l'une des originalités du système français est la place qu'il consent à la déconcentration culturelle, nous étudierons ensuite le contenu et les effets du partenariat État-collectivités territoriales à l'intérieur du cadre régional, dans lequel l'action des directions régionales des affaires culturelles se déploie aujourd'hui. Mais la coopération concerne aussi, bien qu'elle soit encore erratique, les collectivités entre elles, notamment au travers des nouvelles lois qui touchent à l'intercommunalité. On peut, aujourd'hui, en dresser un bilan provisoire dans le domaine culturel.

Le débat sur une nouvelle décentralisation des compétences resterait impressionniste, s'il était privé d'une vue la plus précise possible des instruments réglementant l'intervention des pouvoirs publics en matière de culture. Ceux-ci relèvent, comme les politiques publiques, d'une logique d'empilement historique qui n'en facilite pas la lecture. Nous nous sommes efforcés, en troisième partie, de présenter un tableau synthétique de l'ensemble des règles, compétences et attributions qui sont aujourd'hui soumises à discussion et d'en distinguer les aspects les plus saillants. Chacun pourra donc mesurer l'étendue des dispositions qui sont censées encadrer un secteur réputé peu réglementé, où l'intervention relèverait plus souvent de la stratégie délibérée que de la contrainte légale, quoiqu'il concerne un nombre toujours croissant d'agents publics, d'emplois et d'activités économiques.

\section{I) La culture et ses territoires}

La diversité des niveaux d'action publique culturelle va de pair avec sa persistante disparité, selon le niveau auquel on se réfère, et pour chaque niveau pris isolément. Nous nous limitons ici au rappel de quelques chiffres assortis de commentaires, puis nous analyserons la dynamique actuelle de coopération intercommunale.

5. G. SAEZ, «Villes et culture : un gouvernement par la coopération », Pouvoirs, $\mathrm{n}^{\circ} 73,1995$; R. Rizzardo, La Décentralisation culturelle, Rapport au ministre de la Culture et de la Communication, Paris, La Documentation française, 1990 ; P. Moulinier, Politique culturelle et décentralisation, Paris, CNFPT - La Documentation française, 1995. 


\section{1) Les communes}

Tableau 1

Dépenses culturelles des communes de plus de 10000 habitants (1996)

\section{Illustration non autorisée à la diffusion}

a. Effort culturel : part des dépenses culturelles dans le budget général de la collectivité.

Source : Département des études et de la prospective (DEP) - ministère de la Culture.

Les communes constituent historiquement, et toujours actuellement, le principal niveau d'intervention en matière culturelle. La ventilation de leurs dépenses fait apparaître quatre domaines relativement équilibrés, en pourcentage de leurs budgets culturels totaux :

- la production artistique (musique et danse, spectacle, théâtre) : 18,9\%;

- l'enseignement artistique : $17 \%$;

- les bibliothèques et médiathèques : $16,5 \%$;

- l'animation culturelle (dont les pratiques en amateurs) : $16,1 \%$;

- le patrimoine et les musées : $15,7 \%$.

Il est à noter que ce sont elles qui ont le plus fort niveau de coût de l'administration culturelle, avec $6,8 \%$ du budget qui lui est consacré.

Une autre image de cette importance du niveau communal dans le financement de la politique culturelle nous est donnée par la part que la culture représente en termes d'emploi public : en 1997, 46140 personnes relèvent directement de la filière culturelle, avec une part importante occupée par les directeurs, professeurs et assistants d'enseignement artistique (27 872), et par les agents du patrimoine et des bibliothèques (18 268). Encore ces personnels ne représentent-ils (hors CES et emplois-jeunes) que les agents directement rattachés à la grille, modeste, de la filière culturelle de la fonction publique territoriale. Une très grande partie des directions municipales de la culture sont animées par des personnels ne relevant pas de cette grille. Ce chiffre demeure intéressant à titre de comparaison avec les deux autres niveaux d'administration territoriale.

Ce qui caractérise les politiques municipales de la culture aujourd'hui :

- une proximité avec la demande telle qu'elle s'exprime à l'égard des pouvoirs publics ;

- une conception de service public disposant des moyens d'une offre professionnelle (en ville) ; 80000 habitants.

- une relative homogénéité des stratégies d'action, à partir du niveau de 
Ce modèle de politique urbaine de la culture est actuellement sous tension : l'exiguïté des territoires municipaux par rapport à la structure plus ample des aires urbaines conduit les municipalités à financer des équipements et politiques qui s'adressent de fait à des populations beaucoup plus étendues que celles de leur ressort fiscal. Le poids des charges de centralité justifie la politique de coopération dans ce domaine, tout en la rendant particulièrement difficile à mettre en œuvre (voir plus loin).

Parallèlement, on doit noter que sur l'ensemble du spectre concerné par d'éventuels transferts de compétence, ce sont les communes, et principalement les villes, qui sont sur le devant de la scène. L'exemple de l'enseignement artistique est parlant : elles financent à plus des trois quarts le fonctionnement des conservatoires nationaux de région et écoles nationales de musique, contre 2,9\% pour les conseils généraux et $0,9 \%$ pour les conseils régionaux. Pour les écoles territoriales d'art, ces taux sont respectivement de $68 \%, 3 \%$ et $8 \% 6$.

\section{2) Les conseils généraux}

Tableau 2

Dépenses culturelles des départements en euros (1996)

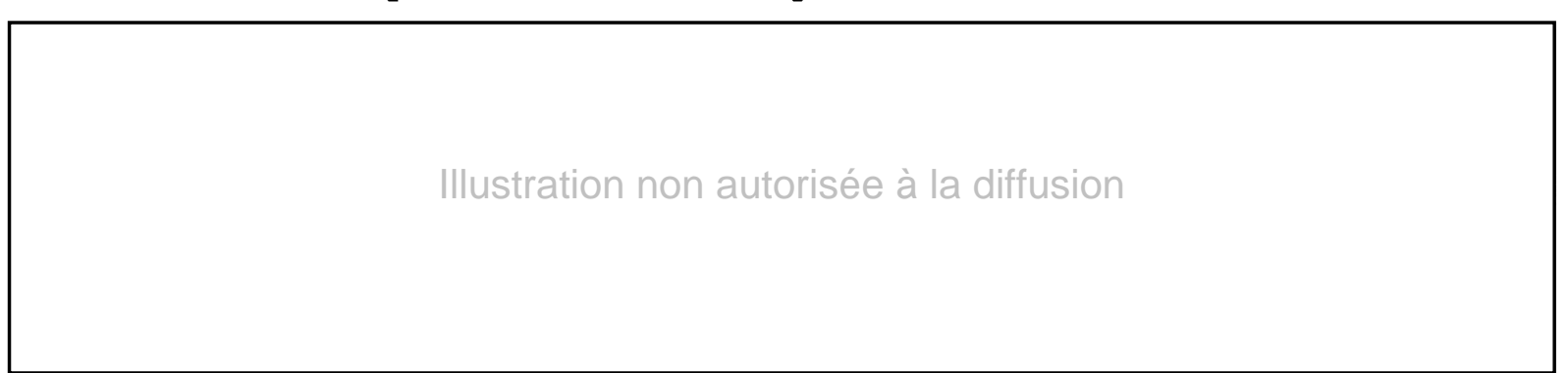

Source : DEP - ministère de la Culture.

Pour l'instant, les départements sont les seules collectivités à avoir bénéficié des transferts de compétence culturelle substantiels : pour les archives et les bibliothèques centrales de prêt ${ }^{7}$. Deux fonctions dominent : la conservation du patrimoine, l'animation polyvalente.

6. Les droits de scolarité ne couvrant respectivement que $7,7 \%$ et $6 \%$ du cout total (chiffres 1998 ), il s'agit donc de volumes cruciaux.

7. Voir J. LE PotTIER, «La décentralisation des archives départementales », in P. POIRRIER et J.-P. Rıoux, Affaires culturelles et territoires, Paris, La Documentation française, 2000, p. 213-254 ; P. Moulinier, « Départements et régions : le tournant des années 1980 », in P. Poirrier et J.-P RiouX, op. cit., p. 101-128; A.-M. BERTRAND, Les Villes et leurs bibliothèques : légitimer et décider (1945-1985), Paris, Electre, Cercle de la Librairie, 1999 ; A.-M. BERTRAND, Bibliothèques départementales de prêt : 50 ans d'aménagement culturel du territoire, Bourg-en-Bresse, Association des directeurs de BDP, 1997. 

on non.

Leurs politiques varient bien sûr en fonction de leur type : urbain, rural, peuplé

C'est un domaine très contrasté, avec une certaine tendance à la convergence : l'écart entre le plus gros financeur départemental et le plus petit était de 1 à 52 en 1975, de 1 à 35 en 1990, de 1 à 20 en 1993. Il tend à se stabiliser aujourd'hui autour de ce dernier écart.

Les départements, au contraire des villes, sont moins directement confrontés à la demande sociale. C'est une demande secondaire (les petites villes, les élus cantonaux) qui la constitue.

Les équipements sont moindres et plus spécifiques : patrimoniaux (monuments, musées, bibliothèques).

Mais, comme les villes, ils gèrent des équipements et emploient un personnel de plus en plus nombreux : 3124 agents de la filière culturelle des collectivités territoriales, dont 147 dans l'enseignement artistique et 2977 dans la lecture publique et le patrimoine (chiffres 1997). On note à ce niveau une tendance croissante à la gestion directe et une diminution des subventions.

Les conseils généraux ne présentent donc pas, contrairement aux villes, un front homogène en dépense culturelle, quoique les contrastes soient en voie de réduction, en termes d'écart financier. Leur investissement dans le champ culturel s'est cependant traduit par un niveau d'encadrement assez important, professionnel, comme en témoigne l'expérience de transfert progressif des compétences en lecture publique et archives, qui s'est globalement traduite par une amélioration des conditions financières et de la qualité de l'offre culturelle sur l'ensemble du territoire. Cette circonstance ne fait pourtant pas des institutions départementales un « régulateur obligé » des politiques culturelles territoriales.

\section{3) Les conseils régionaux}

Tableau 3

Dépenses culturelles des régions (1996)

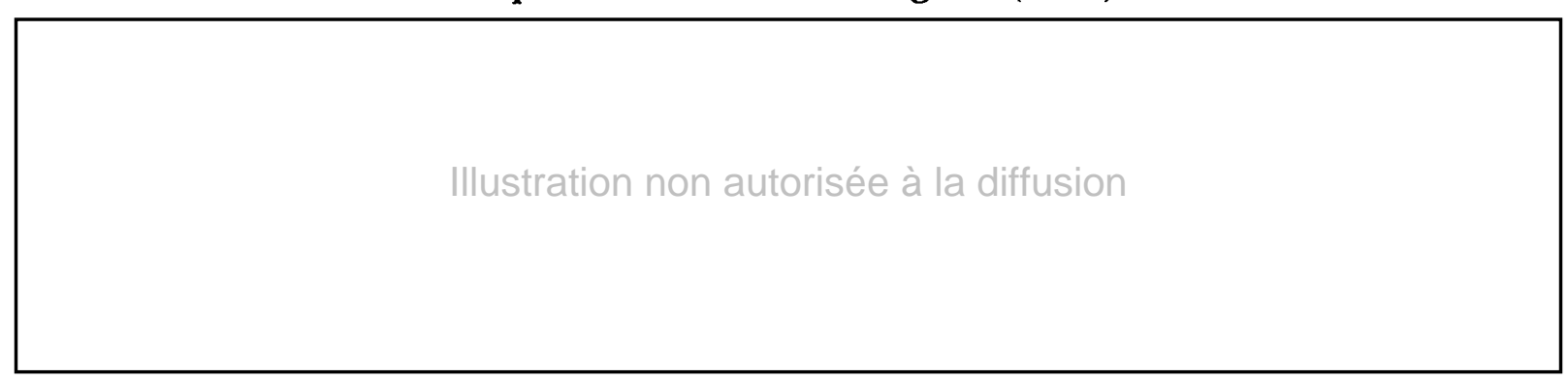

Source : DEP - ministère de la Culture.

La plus récente des collectivités territoriales françaises est aussi celle qui dépense le moins pour la culture dans son budget : $2,4 \%$ en moyenne. C'est égale- 
ment celle qui montre les différences les plus nettes de stratégie et d'investissement dans la culture. Entre celle qui y consacre le moins et celle qui finance le plus la culture, l'écart est de 1 à 14 en francs/habitant ${ }^{8}$. Dans les années 90, certains budgets culturels de région ont même régressé en valeur absolue et en pourcentage, ce qui est un indice assez parlant de fragilité des politiques régionales de la culture.

C'est le niveau où la demande sociale est la plus éloignée et où le poids des subventions l'emporte le plus nettement sur les dépenses de fonctionnement. Un volontarisme de l'État a conduit les régions à développer des fonds (art contemporain, musées) par le biais de la contractualisation, mais on peut dire que les régions sont le maillon faible de l'action culturelle territoriale :

- Elles hésitent généralement entre deux stratégies : leur mission d'aménagement culturel du territoire ou le choix volontariste de certains créneaux étroits (exemples : politique du livre, aide au cinéma, développement des langues régionales...).

- Dans les domaines où elle s'investit pourtant fortement, la région ne dispose pas des capacités politiques de réguler l'action culturelle des autres acteurs (villes et départements). C'est un constat récurrent que le choix de créneaux spécifiques par la région n'a, généralement, eu pour conséquence que d'attiser les rivalités, conflits et mises en œuvre séparées plutôt que de conduire à une logique de « chef de file ». En matière culturelle en tout cas, le « chef-de-filat » demeure un concept énigmatique ${ }^{9}$.

- Dans les cas où elle opte pour une intervention de second rang sur des actions initiées par d'autres acteurs (associations, État, communes ou départements), la faible visibilité de ses interventions va de pair avec une logique de saupoudrage qui laisse prise aux critiques portant sur son clientélisme.

La filière culturelle régionale ne concerne que 152 agents. Pour mémoire, ce niveau d'emploi (auquel il faudrait, comme pour les autres niveaux, ajouter les emplois culturels qui ne relèvent pas de la filière proprement dite) est très largement inférieur, non seulement au niveau départemental (3 124 agents), mais aussi au niveau intercommunal (5 345) de la filière culturelle. Il est donc, en termes d'emploi comme de niveau d'intervention financière, assez paradoxal de mettre en avant une régionalisation qui ne correspond ni à une pratique homogène, ni à une antériorité fondée sur des logiques professionnelles, ni à des capacités d'intervention plus politiques de la part de l'échelon régional.

8. Signalons ici que dans un pays comme l'Espagne, qui a été jusqu'à théoriser le fait différentiel et constitutionnaliser sa pluralité interne, la différence en pesetas par habitant, en 1993, entre la «région» qui dépense le plus (le Pays basque) et celle qui dépense le moins (la Murcie) ne produit un rapport que de 1 à 2,5 .

9. Voir M. PongY, « Les interventions culturelles des régions et des départements », in J. PERRET et J.-P. SAEZ, Institutions et vie culturelle, Paris, La Documentation française, 1996 ; E. NÉGRIER, « Une action publique sans coopération politique. Le style languedocien de politique régionale », $P o ̂ l e ~ S u d, n^{\circ} 8$, Montpellier, Climats, 1998, p. 41-53 ; FORS-Recherches sociales, La Politique culturelle de la région Rhône-Alpes, Rapport d'évaluation pour le conseil régional Rhône-Alpes, Lyon, 1996. 


\section{II) La culture, domaine de coopération publique}

Le gouvernement de la culture par coopération est une réalité qui correspond au moins à deux dimensions : celle des relations de contractualisation et de négociation entre l'État et les collectivités territoriales (la déconcentration), et celle des formes, plus ou moins institutionnalisées, de coopération intercommunale. Le bilan de chacune présente à la fois une évolution ascendante mais aussi des contraintes spécifiques qui permettent de conclure à un certain inaboutissement.

\section{1) L'évolution du partenariat territorial État - collectivités territoriales}

Depuis 1979, l'État dispose sur le territoire d'une administration déconcentrée, par le biais des DRAC (directions régionales des affaires culturelles). Les DRAC ont pour mission officielle de représenter l'État au niveau régional (seul niveau d'administration de la culture), de veiller à la cohérence régionale de son action, de l'évaluer, de conseiller les collectivités territoriales ${ }^{10}$. Sur le plan financier et humain, la déconcentration du ministère de la Culture a évolué de manière nettement positive $^{11}$ après des décennies marquées par plusieurs formes de résistance :

- celle des administrations préfectorales, pour lesquelles l'institutionnalisation de directions « régionales » de la culture était ressentie comme une perte de capacité d'action directe sur le territoire ;

- celle des grands élus, dont la structure cumulative des mandats (local-national) rendait plus attrayante une concentration dans l'administration centrale sur laquelle ils pouvaient influer au détriment de leurs pairs et compétiteurs territoriaux ;

- celle des grands professionnels du secteur culturel, qui voyaient dans la montée en puissance des DRAC une menace de déstabilisation de leurs réseaux internes au ministère.

L'affirmation des DRAC dans le paysage culturel territorial est désormais une réalité. En 2000, elles représentent un effectif de 1857 agents, sur un total de 2486 agents chargés de l'administration générale et sur un total de 22446 agents du ministère, dont 14475 agents titulaires et contractuels, auxquels on doit ajouter les personnels propres des établissements publics administratifs et industriels et commerciaux $^{12}$. Cette déconcentration a incontestablement permis de rapprocher la prise de

10. Voir J.-L. BoDIGUEL, « Naissance et affirmation des directions régionales des affaires culturelles », in P. PoIrrier et J.-P. RIOUX, op. cit., p. 21-56. 2001 .

11. Voir E. DE WARESQUIEL, Dictionnaire des politiques culturelles, Paris, Larousse - CNRS Éditions,

12. Voir J. Cardona et C. Lacroix, Chiffres clefs 2001, Paris, ministère de la Culture, La Documentation française, 2002. 
décision de son lieu de mise en œuvre, comme elle a rendu possible une certaine globalisation, en région, de la politique culturelle ${ }^{13}$. Des dispositifs comme les schémas de service collectifs culturels, les contrats de plan État-région traduisent cette hypothèse en réalité, même si ces innovations sont parfois détournées de leurs objectifs, ou soumises aux contraintes du jeu politico-administratif. Quatre contraintes principales marquent le fonctionnement du partenariat du point de vue des DRAC :

- La réalité de la déconcentration est parfois douteuse ${ }^{14}$, lorsque les fonds qui sont transférés sont déjà préaffectés : la marge de manœuvre des DRAC est ainsi réduite, voire inexistante dans certains domaines où elle bénéficie de fonds en théorie (exemple: la plupart des financements au titre d'actions internationales); par ailleurs, la déconcentration des moyens financiers ne s'est pas accompagnée d'une déconcentration équivalente des personnels pour en assumer la gestion. Ce qui conduit à une administration culturelle régionale sous pression permanente, notamment dans les domaines non patrimoniaux.

- La persistance d'une organisation verticale du ministère par secteurs, qui rendent les DRAC très difficiles à gouverner d'un point de vue régional : les conseillers de secteurs continuent d'en référer à leur Direction nationale, plutôt que de « jouer » une stratégie régionale.

- La difficulté propre à cette «nouvelle » administration d'agir de manière systématique sur son territoire régional. L'esprit de combat (d'exception) et la logique de projet, qui ne sont parfois qu'un voile pudique jeté sur la rareté des financements publics culturels, vont de pair avec une très inégale répartition de l'effort culturel entre DRAC sur l'espace français, et avec une sélectivité de cet effort au sein de chaque territoire régional.

- La logique sectorielle « culture » s'adapte parfois difficilement à la réalité du développement des politiques territoriales. L'essor des collectivités et de leurs professionnels n'est pas toujours pris en compte de manière optimale par les agents culturels de l'État, qui préfèrent parfois, quand ils le peuvent, s'abriter derrière la détention d'une compétence régalienne plutôt que de s'impliquer dans un rapport d'interdépendance, auquel l'exiguïté financière les contraint pourtant de plus en plus. C'est la raison pour laquelle ce sont souvent les services patrimoniaux des Monuments historiques qui sont les plus réticents à l'hypothèse d'un réel transfert de compétence.

Une déconcentration en trompe-l'œil, une sectorisation qui résiste au territoire, des corporatismes jaloux de leur autonomie, tels sont les aspects critiques (ici grossièrement décrits) des politiques culturelles de l'État en région. Pourtant, ce constat ne doit pas masquer une autre réalité, celle d'un jeu à double détente entre l'État et ses partenaires territoriaux. Leur interdépendance est également liée à un registre moins

13. R. LATARJET, L'Aménagement culturel du territoire, Paris, La Documentation française, 1992.

14. Au-delà du fait même que plus de la moitié du budget culturel de l'État soit en réalité dépensé sur Paris intra-muros. 
visible mais tout aussi important à signaler dans le contexte d'une réflexion exploratoire sur le transfert de certaines compétences. Elle s'exprime de la façon suivante :

- L'État n'est plus maître du jeu économique de la culture. Il détient néanmoins un certain nombre de capacités d'expertise, de labellisation, de soutien financier, de même qu'un pouvoir d'empêcher, dont il ne peut pourtant user de manière unilatérale, sauf exception, notamment dans le domaine patrimonial. L'usage de telles capacités s'inscrit au cour de l'interaction avec les pouvoirs locaux. Leur négociation a pour finalité l'extension des moyens à destination de projets que les agents de l'État estiment correspondre à leurs critères d'excellence. C'est la raison pour laquelle certaines formes de troc peuvent exister, au sujet du pouvoir de nomination comme à l'égard de financements de certaines actions culturelles.

- Les collectivités investissent le champ de la culture pour des motifs en partie convergents avec les objectifs de l'État (soutien à la création, implication de nouveaux publics, aménagement culturel du territoire), et en partie spécifiques: constitution d'une image attractive du territoire, stratégie de développement économique, autopromotion d'un exécutif politique ${ }^{15}$. Pour des raisons financières (logique de guichet) ou symboliques (valorisation du label qualitatif de l'État), la collectivité place, elle aussi, ses objectifs propres en interaction avec celles de l'État. À sa manière, elle en négocie la mise en œuvre. Mais cette collectivité n'est pas monolithique. Elle est faite à la fois d'élus et d'agents administratifs professionnels, et ces derniers inscrivent le partenaire État dans un jeu triangulaire : élus-administrateurs locaux-agents de l'État. La faculté qu'a l'État de dire non, de refuser un soutien, parfois même contre l'évidence des discours officiels des agents ${ }^{16}$, est bel et bien une ressource pour des agents qui, désireux de résister à certains choix de leurs élus, n'en ont pourtant ni les moyens ni la légitimité, si ce n'est en recourant à l'intervention (« scandaleuse », « arbitraire »...) de l'État, notamment sous l'angle des compétences légales qu'il exerce de plein droit.

\section{2) La culture dans la coopération intercommunale}

Poussive, cosmétique parfois, labyrintique souvent, la coopération entre collectivités territoriales est longtemps restée étrangère au secteur culturel ${ }^{17}$. Trop intéressés à tirer le parti politique d'actions menées dans un champ aussi chargé de symboles

15. Voir L. BONET et E. NÉGRIER, « Lobservation culturelle face à la globalisation. Quelles sources d'information pour évaluer quels objectifs de politique culturelle ? », Montréal, Colloque international sur les statistiques culturelles, octobre 2002 .

16. On fait ici référence à la litanie des fameux « critères incompréhensibles » de la DRAC, qui masque souvent une parfaite connaissance de cause.

17. Voir ObSERVATOIRE DES POLITIQUes CUltuRElles, Action culturelle et coopération intercommunale, OPC-DEP, Paris, La Documentation française, 1992 ; M. VERPEAUX, «Intercommunalité et service public culturel », in AJDA, numéro spécial, Culture et service public, 2000, p. 115-124. 
positifs, les élus n'étaient pas pressés d'en partager les fruits. Sans réelle obligation d'agir dans tel ou tel domaine, les pouvoirs locaux n'ont pas vraiment ajusté leurs politiques en fonction de celles des autres niveaux, quand ils n'ont pas, précisément, joué d'une concurrence débridée sur les mêmes créneaux. Simultanéité de festivals destinés aux mêmes publics, équipements concentrés sur les mêmes zones, dépenses d'investissements somptuaires sans égards pour les contraintes de fonctionnement ou le souci d'aménagement culturel du territoire... constituent l'héritage, parfois caricatural, d'un tel état de fait ${ }^{18}$. Il ne faut cependant pas noircir le tableau de ces dérives de l'action culturelle libre dans le territoire libre. Son absence de généralisation s'explique par un certain rôle de régulation que, malgré tout, l'État a pu jouer. Elle se comprend aussi comme l'un des effets de la professionnalisation des politiques culturelles, et donc de la capacité de résistance des agents à certains projets, tout autant que certains rappels, fiscalement douloureux, à la règle budgétaire. Parallèlement à ce tableau grisâtre du partenariat « vertical » entre niveaux, s'est progressivement instillée une dose de partenariat horizontal, sur lequel il nous semble important de nous pencher maintenant, en dressant un bilan qualitatif des deux lois de 1999 touchant à la coopération intercommunale : la loi d'orientation pour l'aménagement et le développement durable du territoire, du 25 juin 1999, et la loi relative au renforcement et à la simplification de la coopération intercommunale du 12 juillet $1999^{19}$.

La loi Chevènement fait de la culture un domaine de compétence optionnelle des communautés d'agglomération et de communes, tandis qu'il s'agit d'un domaine de compétence obligatoire pour les communautés urbaines.

Alors que l'on pouvait s'attendre à un mouvement relativement timide dans ce domaine, si l'on en juge par les expériences passées d'intercommunalité urbaine, la culture a été retenue dans une large majorité de communautés. À cet élément positif, il faut immédiatement apporter le double correctif suivant :

- la prise de compétence «culture » est encore bien souvent une coquille vide, prise « pour voir » sans déclencher partout, loin s'en faut, une véritable dynamique de gestion collective, et encore moins une réelle innovation en termes de contenu des politiques culturelles ;

- les agglomérations les plus dynamiques sont encore aujourd'hui confrontées à un enjeu de partage à plusieurs d'une politique préexistante plus qu'à la reformulation, partielle ou intégrale, des principes et modalités de leur intervention dans ce champ.

18. Voir P. LE GALÈs, « Rennes : catholic humanism and urban entrepreneurialism », in F. BIANCHINI et M. Parkinson, Cultural Policies and Urban Regeneration, Manchester University Press, 1993 , p. 178-198; E. NEGRIER, «Montpellier : international competition and community access », in F. BIANChini et M. PARKInson, op. cit., p. 135-154; E. NÉgrier, « Une manifestation musicale au miroir de la ville. Le festival de Radio-France et (de) Montpellier », in A. DARRE (dir.), Musiques et politique. Les répertoires de l'identité, Rennes, Presses universitaires de Rennes, 1996, p. 127-148.

19. Voir A. FAURe et E. NÉGrier (dir.), La Politique culturelle des agglomérations, Paris, La Documentation française, 2001. 
La loi Voynet fait des pays des territoires de projet, au contraire des communautés de communes et d'agglomérations qui sont, en dépit du maintien du principe de spécialité de leurs compétences, de réelles nouvelles institutions, dont on peut penser qu'elles préfigurent un nouveau niveau d'action publique intégré. Les pays ont a priori un rapport beaucoup plus étroit à la question culturelle, puisqu'il leur est fait obligation d'inscrire le choix de leur périmètre dans une pertinence « vécue », ce que bien des projets ont traduit par l'évocation d'une communauté de proximité, de partage de traditions... bref d'un patrimoine commun. C'est le jeu sur cette cohérence historico-patrimoniale qui explique que la carte des pays projetés recoupe, très souvent, les territoires pré-révolutionnaires ${ }^{20}$. Pour autant, le passage d'une logique de « l'évocation culturelle » à la notion de «politique culturelle », de programmation d'une nouvelle action publique à l'échelle de ce territoire de projet, demeure rare, délicate, faiblement mobilisatrice. On peut l'expliquer par trois raisons :

- Le passage de l'évocation patrimoniale à une véritable action dans ce domaine pose des difficultés de type économique (le coût de la mise en œuvre d'une politique de conservation ou de mise en valeur), politique (la mise en œuvre de choix forcément discriminants sur le territoire qui induit la valorisation de certaines parties du territoire), institutionnel (les décalages existant entre les velléités d'intervention des acteurs de terrain et les exigences des corps de professionnels des Monuments historiques), cognitif (l'hétérogénéité des représentations de ce qu'est le patrimoine culturel entre les différents acteurs qui participent ou sont appelés à participer à ces opérations).

- La co-occurrence des deux lois, qui concerne grosso modo les mêmes acteurs (en tout cas dans la sphère municipale), conduit ces derniers à opérer des choix. Ceux-ci sont dictés par l'absence d'un statut de l'élu qui rend extrêmement tendus les agendas politiques locaux. En conséquence, ces acteurs tendent à se mobiliser davantage sur les enjeux de type institutionnel lourd, comme le sont les communautés de communes ou d'agglomérations, plutôt que sur les pays. On peut en voir une preuve supplémentaire en observant que, bien souvent, un pays est projeté précisément là où les difficultés d'un passage direct à une formule institutionnelle lourde font problème.

- Le pays peut apparaître comme une réponse «provisoire » à une carte locale incohérente ou sous-optimale. En effet, aucune agglomération ne rayonne aujourd'hui à l'échelle des aires urbaines, ces dernières étant en conséquence constituées de plusieurs intercommunalités sinon conflictuelles, du moins de destin séparé. Le recours au pays peut donc être lié à l'idée d'une gestion commune, mais minimale, de certains enjeux d'aménagement (PDU, SCOT ${ }^{21} \ldots$...) tandis que la « vraie » compétence est affaire de communes et d'intercommunalité institutionnelle.

20. Voir J.-Y. Nevers, «La relance de l'intercommunalité. Contextes et stratégies », in R. BALME, A. Faure et A. Mabileau, Les Nouvelles Politiques locales, Paris, Presses de Science Po, 1999, p. $221-231$.

21. PDU : plan de déplacements urbains ; SCOT : schéma de cohérence territoriale. 
En conséquence, l'articulation actuelle entre les lois Voynet et Chevènement se fait a minima et « par le bas ». Et cette situation est largement défavorable à la dynamique « culturelle » des pays.

Plus dynamique en application de la loi Chevènement, l'intercommunalité culturelle se traduit par des modèles également très différenciés sur le terrain. On peut en effet, sur la base de l'existant, indiquer au moins trois scénarios en train de se dérouler, au gré des territoires, à la faveur de la prise de compétence culturelle.

\section{A) La simple réduction des charges de centralité}

C'est le modèle le moins innovant ; le plus logique à court terme ; la culture est ici marchandée avec le sport, les transports, les équipements de voirie... L'instance intercommunale a un budget, une compétence, mais pas de politique propre. C'est un guichet, un fonds de concours de la politique de la ville centre, où restent les professionnels et l'essentiel des cadres administratifs. Ce modèle renforce la prééminence du centre ; il est pour une part nécessaire dans un premier temps, ne serait-ce que pour réconcilier le financement des structures et leur pratique territoriale par les populations. Mais il sera sans doute rapidement limité, voire contraint politiquement ; un passage obligé, en quelque sorte.

\section{B) L'extension culturelle sélective}

Outre la réduction des charges de centralité, la communauté se dote de compétences propres, qu'elle exerce de plein droit, dans des domaines ciblés. Elle assure la définition de la politique, son financement et sa mise en œuvre. Sont par exemple concernés :

- la lecture publique (réseau de médiathèques) ;

- l'enseignement artistique (réseau d'écoles de musique);

- l'aménagement théâtral du territoire aggloméré ;

- un grand équipement d'agglomération (centre d'art contemporain, scène nationale, centre pluridisciplinaire...);

- une politique transversale : culture et politique de la ville, inventaire patrimonial et voirie...

Dans ce modèle, l'agglomération gagne en autonomie, sa définition d'une politique conduit à un débat, et les difficultés les plus grandes sont liées à la mise en œuvre : rapport centre-périphérie, réaction des professionnels, des élus... Ici aussi, l'agglomération est sélectivement dotée de moyens humains et financiers propres.

\section{C) La politique culturelle intégrée}

Apparemment le plus improbable des scénarios. Les élus restent attachés à leurs politiques culturelles, à leurs réseaux associatifs culturels, qui constituent, avec les associations sportives, l'une de leurs plus sûres bases électorale. Les profession- 
nels n'y poussent pas, rechignent à changer facilement d'interlocuteur. Ce scénario est un aboutissement possible d'un processus par étapes, d'apprentissages multiples, de partage de références communes entre élus...

Un tel modèle est subsidiaire, inversé : tout ce qui est culturel est d'agglomération, sauf démonstration contraire. Il est donc puissamment légitimant pour les communautés nouvelles.

Or celles-ci ne sont pas, aujourd'hui, dirigées par les élus d'un suffrage universel direct. La compétence maximale doit s'accompagner d'une légitimité maximale. Ce n'est pas le cas aujourd'hui.

Ces dispositifs de coopération sont, à leur manière et quoique balbutiants, au cœur des nouveaux enjeux de politique culturelle territoriale ; et ce pour au moins trois raisons : ils manifestent l'exploration de voies nouvelles afin d'atteindre des objectifs de politique publique considérés comme globalement consensuels; ils s'attaquent, le plus souvent, à l'un des thèmes majeurs de la redéfinition de l'offre de service public culturel - sa diffusion à la périphérie des villes ; ils s'appuient sur des compétences définies, même si elles ne sont ni exclusives ni figées dans l'airain légal.

État central, DRAC, régions, villes et départements, intercommunalités, associations et professionnels de structures privées... Tout dans ce tableau illustre ce que les Anglo-Saxons appellent un overcrowded policy-making, un surnombre d'acteurs pour des politiques à la fois légitimes et fragiles. C'est bien sûr le signe d'un réel enthousiasme pour l'impératif culturel, et en même temps la sanction d'un régime reposant essentiellement sur la liberté d'initiative.

C'est dans ce contexte imbriqué de longue date qu'a surgi sur l'agenda politique une offre de débat visant une nouvelle répartition des compétences. Afin d'éclairer les termes de ce débat, il n'est pas inutile de présenter synthétiquement quels sont les termes juridiques de ce débat politique.

\section{III) Le droit des politiques culturelles : la répartition actuelle des compétences}

Il résulte de ce qui précède que l'essentiel des compétences publiques en matière culturelle relève de la liberté d'initiative. Certes celle-ci est-elle encadrée par un certain nombre de dispositions légales et réglementaires, dont certaines ont traversé sans refonte réelle deux guerres mondiales et trois Républiques, comme la fameuse loi du 31 décembre 1913 sur le patrimoine ${ }^{22}$. Mais la dynamique culturelle

22. Voir R. LECAT, « Le contrôle de l'État par la norme », AJDA, numéro spécial, Culture et service public, 2000, p. 95-102 ; A.-H. MESNARD, « L'harmonisation des politiques culturelles », ibid., p. 103-114. 
ne procède que marginalement d'injonctions à $\operatorname{agir}^{23}$. En ce domaine, la forte implication des pouvoirs publics résulte davantage d'un consensus sur la légitimité d'intervenir dans le champ culturel, quand bien même ce consensus n'induirait pas une convergence des objectifs et outils de cette intervention. Aussi les obligations d'agir dans ces différents cadres sont-elles relativement limitées, tant sont généraux et imprécis les objectifs (exemple : démocratisation culturelle, aménagement culturel du territoire) qu'ils assignent. Par ailleurs, la détention d'une compétence légale est loin d'être synonyme de pouvoir exclusif. Dans une très grande partie des aspects de politique culturelle, la capacité légale intervient en complément nécessaire d'une capacité d'intervention qui est, dans la plupart des domaines, partagée entre plusieurs niveaux d'action publique. Le partenariat est d'autant plus la règle que l'on envisage les domaines moins réglementés, ou ceux, tels le spectacle vivant, pour lesquels la loi n'a pas doté l'État de compétences dites « régaliennes », comme pour les Monuments historiques. Aussi toute nouvelle étape de décentralisation culturelle doit-elle certes intégrer les aspects juridiques, mais en énoncer en même temps la grande relativité. Les tableaux suivants décrivent, domaine par domaine, l'essentiel des règles de compétence et de partenariat entre l'État et les différentes collectivités territoriales. Cette série est largement inspirée d'un travail effectué par Pierre Moulinier pour le compte de l'Observatoire des politiques culturelles de Grenoble, à l'automne $2001^{24}$, que nous avons partiellement actualisé.

Ces tableaux sont un état synthétique de l'étendue des domaines dans lesquels les pouvoirs publics interviennent, qu'ils y soient contraints ou qu'ils en aient la libre initiative (au sens légal et constitutionnel du terme), et des compćtences, exclusives ou partagées, précises ou plus floues, qui s'y rattachent. On peut d'ores et déjà en tirer plusieurs constats :

- La très grande majorité des domaines fait intervenir les quatre catégories de pouvoir public, et cela alors même que nous n'avons pas intégré dans le tableau les diverses formes d'intercommunalité.

- L'intervention de l'État est plus souvent marquée par un degré d'obligation et par la présence d'institutions chargées de la mettre en œuvre. Cependant, en termes de chiffres, la majeure partie $(85 \%)$ des 8500 organismes qui participent à la mise en œuvre des différents aspects de politique culturelle relèvent des collectivités territoriales.

- Les fonctions, à l'intérieur des domaines, qui manifestent une compétence propre de l'État sont régulièrement les suivantes : contrôle, inspection, conseil, expertise, codification, réglementation et, dans une moindre mesure, formation (notamment supérieure).

23. P. Baleynaud, « La culture : l'oubliée de la décentralisation ? », Revue du droit public et de la science politique en France et à l'étranger, $\mathrm{n}^{\circ}$ 1, 1991, p. 149-195 ; P.-L. FRIER, « La répartition actuelle des compétences entre l'État et le pouvoir local », $A J D A$, numéro spécial précité, p. 58-69.

24. Voir P. Moulinier, « Compétences et modes d'action de l'État et des collectivités territoriales en matière de culture », Les Cahiers de l'Observatoire des politiques culturelles, supplément au $n^{\circ} 21,2001$. 
Tableau 4

Répartition des compétences par domaines en matière de culture - Systèmes d'action transversaux

\begin{tabular}{|c|c|c|c|c|}
\hline Domaines & État & Communes & Départements & Régions \\
\hline $\begin{array}{l}\text { Aménagement } \\
\text { culturel du territoire }\end{array}$ & $\begin{array}{l}\text { Volets culturels des CPER - mise en œuvre des schémas } \\
\text { régionaux des services collectifs culturels, loi } 25 \text { juin } 1999\end{array}$ & & $\begin{array}{l}\text { CPER volet } \\
\text { départemental }\end{array}$ & CPER volet régional \\
\hline $\begin{array}{l}\text { Culture scientifique } \\
\text { et technique }\end{array}$ & Cité des sciences et techniques de la Villette & $\begin{array}{l}\text { Centres et musées, } \\
\text { associations }\end{array}$ & $\begin{array}{l}\text { Centres et musées } \\
\text { départementaux }\end{array}$ & $\begin{array}{l}\text { Centres et musées } \\
\text { régionaux }\end{array}$ \\
\hline Tourisme culturel & $\begin{array}{l}\text { Convention Culture-Tourisme - aide à festivals, } \\
\text { labels VPAH }\end{array}$ & Offices du tourisme & $\begin{array}{l}\text { Comités départemen- } \\
\text { taux du tourisme }\end{array}$ & $\begin{array}{l}\text { Comités régionaux } \\
\text { du tourisme }\end{array}$ \\
\hline Milieu pénitentiaire & $\begin{array}{l}\text { Convention Culture-Justice - aides aux actions en milieu } \\
\text { pénitentiaire }\end{array}$ & Intervention possible & Intervention possible & Intervention possible \\
\hline Milieu hospitalier & $\begin{array}{l}\text { Convention Culture-Santé - aides aux actions dans } \\
\text { les hôpitaux et en faveur des handicapés }\end{array}$ & Intervention possible & Intervention possible & Intervention possible \\
\hline Milieu rural & $\begin{array}{l}\text { Convention Culture-Agriculture, actions dans les lycées } \\
\text { agricoles, relais-livre en milieu rural }\end{array}$ & $\begin{array}{l}\text { Soutien aux associa- } \\
\text { tions - Relais livre } \\
\text { en milieu rural }\end{array}$ & $\begin{array}{l}\text { Soutien au développe- } \\
\text { ment culturel - Relais } \\
\text { livre en milieu rural }\end{array}$ & Intervention possible \\
\hline Politique de la ville & $\begin{array}{l}\text { Contrats de ville, actions spécifiques : contrats ville-lecture, } \\
\text { « un été au ciné »... }\end{array}$ & Contrats de ville & Intervention possible & Contrats de ville \\
\hline $\begin{array}{l}\text { Jeunesse } \\
\text { et petite enfance }\end{array}$ & $\begin{array}{l}\text { Contrats ville-enfants avec communes et ministère de } \\
\text { la Jeunesse et des Sports }\end{array}$ & Contrats ville-enfants & & Intervention possible \\
\hline Éducation artistique & $\begin{array}{l}\text { Conventions Culture-Éducation - loi sur les enseignements } \\
\text { artistiques du } 6 \text { janvier 1988, contrats locaux d'éducation } \\
\text { artistique, formation des intervenants musicaux, ateliers } \\
\text { et classes à PAC }\end{array}$ & $\begin{array}{l}\text { Contrats locaux } \\
\text { d'éducation artistique }\end{array}$ & Intervention possible & Intervention possible \\
\hline $\begin{array}{l}\text { Relations culturelles } \\
\text { internationales }\end{array}$ & $\begin{array}{l}\text { MAE - DG CID Réseau culturel ; Association française } \\
\text { d'action artistique, MCNG, DAI du ministère de la Culture }\end{array}$ & $\begin{array}{l}\text { Intervention possible } \\
\text { Coopération } \\
\text { décentralisée } \\
\text { Partenariat AFAA }\end{array}$ & $\begin{array}{l}\text { Intervention possible } \\
\text { Coopération } \\
\text { décentralisée } \\
\text { Partenariat AFAA }\end{array}$ & $\begin{array}{l}\text { Intervention possible } \\
\text { Coopération } \\
\text { décentralisée } \\
\text { Partenariat AFAA }\end{array}$ \\
\hline
\end{tabular}


Tableau 4

Répartition des compétences par domaines en matière de culture - Systèmes d'action transversaux (suite)

\begin{tabular}{|c|c|c|c|c|}
\hline Domaines & État & Communes & Départements & Régions \\
\hline $\begin{array}{l}\text { Langue française } \\
\text { et langues régionales }\end{array}$ & $\begin{array}{l}\text { Lois des } 11 \text { janvier } 1951 \text { et } 4 \text { août 1994, Conseil national } \\
\text { des langues et cultures régionales }\end{array}$ & Intervention possible & Intervention possible & Intervention possible \\
\hline $\begin{array}{l}\text { Communication } \\
\text { et nouvelles } \\
\text { technologies }\end{array}$ & Code de la communication, loi du 2 août 2000 & $\begin{array}{l}\text { Développement } \\
\text { d'espaces multimédia }\end{array}$ & Intervention possible & Intervention possible \\
\hline $\begin{array}{l}\text { Propriété } \\
\text { intellectuelle }\end{array}$ & Code de la propriété intellectuelle, loi du 3 juillet 1985 & & & \\
\hline Marché de l'art & $\begin{array}{l}\text { Convention européenne Delphes 1985, Directive européenne } \\
\text { du } 16 \text { mars 1993, lois : } 30 \text { novembre 1987, } 31 \text { décembre } \\
1992 \text { et } 10 \text { juillet } 2000 \text {, décret } 25 \text { mars } 1997\end{array}$ & & & \\
\hline Mécénat et fondation & Loi des 23 juillet 1987 et 4 juillet 1990 & Intervention possible & Intervention possible & Intervention possible \\
\hline Fonction publique & $\begin{array}{l}\text { Loi des } 12 \text { juillet et } 27 \text { décembre 1994, } \\
\text { Réglementation et Centres de formation de l'État }\end{array}$ & CNFPT & CNFPT & CNFPT \\
\hline Formation des acteurs & Formation continue ministère de la Culture, universités & $\begin{array}{l}\text { CNFPT, associations } \\
\text { d'élus }\end{array}$ & $\begin{array}{l}\text { CNFPT, associations } \\
\text { d'élus }\end{array}$ & $\begin{array}{l}\text { CNFPT, centres } \\
\text { d'aide gestion }\end{array}$ \\
\hline Études & DEP ministère de la Culture, université, CNRS & Intervention possible & Intervention possible & Intervention possible \\
\hline
\end{tabular}


Tableau 5

Répartition des compétences par domaines en matière de culture - Systèmes d'action sectoriels

\begin{tabular}{|c|c|c|c|c|}
\hline Domaines & État & Communes & Départements & Régions \\
\hline Architecture & $\begin{array}{l}\text { Réglementation de la profession (loi du } 3 \text { janvier 1977) } \\
\text { Enseignement (écoles d'architecture) } \\
\text { Veille à la qualité de l'architecture : organe interministériel } \\
\text { Développement de la création architecturale } \\
\text { Conseil, recherche, sensibilisation (DAPA et DRAC) } \\
\text { Expertise (inspection, DRAC, SDAP) }\end{array}$ & $\begin{array}{l}\text { Partenariat important } \\
\text { (ex. Maisons de } \\
\text { l'architecture...) } \\
\text { Agences d'urbanisme }\end{array}$ & $\begin{array}{l}\text { Partenariat important } \\
\text { (CAUE) }\end{array}$ & Partenariat possible \\
\hline $\begin{array}{l}\text { Archives } \\
\text { - réglementation } \\
\text { et service public }\end{array}$ & $\begin{array}{l}\text { Réglementation : loi du } 3 \text { janvier } 1979 \\
\text { Service public : Archives nationales, aides territoriales } \\
\text { Contrôle scientifique DAF : loi du } 22 \text { juillct } 1983\end{array}$ & $\begin{array}{l}\text { Archives municipales } \\
\text { (oblig.) }\end{array}$ & $\begin{array}{l}\text { Archives } \\
\text { départementales }\end{array}$ & Archives régionales \\
\hline $\begin{array}{l}\text { Archives } \\
\text { - recherche, } \\
\text { conservation... }\end{array}$ & $\begin{array}{l}\text { Archives nationales, aides aux inventaires, à la restauration, } \\
\text { à la numérisation }\end{array}$ & Archives municipales & $\begin{array}{l}\text { Archives } \\
\text { départementales }\end{array}$ & \\
\hline $\begin{array}{l}\text { Archives } \\
\text { - formation } \\
\text { professionnelle }\end{array}$ & $\begin{array}{l}\text { École nationale des Chartes, École nationale du Patrimoine } \\
\text { et autres formations universitaires }\end{array}$ & & & \\
\hline $\begin{array}{l}\text { Archives } \\
\text { - action éducative }\end{array}$ & Archives nationales & $\begin{array}{l}\text { Archives municipales } \\
\text { (services éducatifs, } \\
\text { expositions...) }\end{array}$ & $\begin{array}{l}\text { Archives départemen- } \\
\text { tales (services éduca- } \\
\text { tifs, expositions...) }\end{array}$ & Intervention possible \\
\hline $\begin{array}{l}\text { Arts Plastiques } \\
\text { - enseignement }\end{array}$ & Établissements publics de l'État, aides aux écoles territoriales & Écoles d'art & & Écoles d'art \\
\hline $\begin{array}{l}\text { Arts plastiques } \\
\text { - contrôle pédagogique }\end{array}$ & Délégation aux Arts plastiques, ministère de la Culture & & & \\
\hline $\begin{array}{l}\text { Arts plastiques } \\
\text { - commande publique }\end{array}$ & Commande publique, obligation du $1 \%$ constructions État & $\begin{array}{l}\text { Commande publique, } \\
\text { obligation du } 1 \% \\
\text { (écoles) }\end{array}$ & $\begin{array}{l}\text { Commande publique, } \\
\text { obligation du } 1 \% \\
\text { (collèges) }\end{array}$ & $\begin{array}{l}\text { Commande publique, } \\
\text { obligation du } 1 \% \\
\text { (lycées) }\end{array}$ \\
\hline
\end{tabular}


Tableau 5

Répartition des compétences par domaines en matière de culture - Systèmes d'action sectoriels (suite)

\begin{tabular}{|c|c|c|c|c|}
\hline Domaines & État & Communes & Départements & Régions \\
\hline $\begin{array}{l}\text { Arts plastiques } \\
\text { - aide à création }\end{array}$ & Fonds d'aide, soutien à création d'ateliers d'artistes & Intervention possible & Intervention possible & Intervention possible \\
\hline $\begin{array}{l}\text { Arts plastiques } \\
\text { - diffusion }\end{array}$ & FRAC, aides aux centres d'art & Centres d'art & & FRAC \\
\hline $\begin{array}{l}\text { Arts plastiques } \\
\text { - pratiques amateurs }\end{array}$ & & Intervention possible & Intervention possible & Intervention possible \\
\hline $\begin{array}{l}\text { Arts plastiques } \\
\text { - conseil }\end{array}$ & Conseillers AP DRAC & & & \\
\hline Cinéma, audio-visuel & $\begin{array}{l}\text { Organisation (CNC, Code du Cinéma), soutien (réglementa- } \\
\text { tion, SOFICA), Parc (multiplexes, aide aux collectivités } \\
\text { territoriales : lois des } 5 \text { juillet } 1996 \text { et } 13 \text { juillet 1992) } \\
\text { Formation : ENSMIS et universités } \\
\text { Aides à la diffusion de la culture cinématographique } \\
\text { Conseil : délégations régionales CNC, conseillers DRAC }\end{array}$ & $\begin{array}{l}\text { Intervention possible } \\
\text { (salles municipales, } \\
\text { subventions) et } \\
\text { conventions } \\
\text { État-ville, actions } \\
\text { scolaires, quartiers }\end{array}$ & $\begin{array}{l}\text { Intervention possible } \\
\text { (subventions, circuits } \\
\text { itinérants) } \\
\text { conventions État-CG, } \\
\text { actions scolaires }\end{array}$ & $\begin{array}{l}\text { Intervention possible } \\
\text { (aides à la création } \\
\text { et production) }\end{array}$ \\
\hline $\begin{array}{l}\text { Livre et Lecture } \\
\text { - contrôle }\end{array}$ & $\begin{array}{l}\text { Direction du Livre et de la Lecture, ministère de la Culture } \\
\text { Loi du } 22 \text { juillet } 1983\end{array}$ & & & \\
\hline $\begin{array}{l}\text { Livre et Lecture } \\
\text { - établissements }\end{array}$ & BNF, BPI & $\begin{array}{l}\text { Bibliothèques, média- } \\
\text { thèques, BMVR }\end{array}$ & BDP & Intervention possible \\
\hline $\begin{array}{l}\text { Livre et Lecture } \\
\text { - patrimoine litt. }\end{array}$ & $\begin{array}{l}\text { Bibliothèques à vocation patrimoniale (BNF) ; } \\
\text { aides aux inventaires, à la restauration, à la numérisation }\end{array}$ & $\begin{array}{l}\text { Bibliothèques à } \\
\text { vocation patrimoniale }\end{array}$ & Intervention possible & $\begin{array}{l}\text { Fonds régionaux } \\
\text { d'acquisition, } \\
\text { agences de coop. }\end{array}$ \\
\hline $\begin{array}{l}\text { Livre et Lecture } \\
\text { - formation prof. }\end{array}$ & ENSSIB, formations universitaires, divers... & Intervention possible & & \\
\hline
\end{tabular}


Tableau 5

Répartition des compétences par domaines en matière de culture - Systèmes d'action sectoriels (suite)

\begin{tabular}{|c|c|c|c|c|}
\hline Domaines & État & Communes & Départements & Régions \\
\hline $\begin{array}{l}\text { Livre et Lecture } \\
\text { - économie du livre }\end{array}$ & $\begin{array}{l}\text { Prix Unique réglementé, aides librairies, } \\
\text { aides CNL à l'édition }\end{array}$ & Intervention possible & Intervention possible & $\begin{array}{l}\text { Intervention possible } \\
\text { (Centres régionaux } \\
\text { des Lettres) }\end{array}$ \\
\hline $\begin{array}{l}\text { Livre et Lecture } \\
\text { - développement } \\
\text { de la lecture }\end{array}$ & $\begin{array}{l}\text { Aides DRAC, accords interministériels, } \\
\text { contrats ville-lecture... }\end{array}$ & $\begin{array}{l}\text { Intervention possible } \\
\text { (services éducatifs des } \\
\text { bibliothèques, résiden- } \\
\text { ces d'écrivains...) }\end{array}$ & $\begin{array}{l}\text { Intervention possible } \\
\text { (rôle des BDP, } \\
\text { relais-livre en milieu } \\
\text { rural...) }\end{array}$ & Intervention possible \\
\hline $\begin{array}{l}\text { Musées } \\
\text { - équipements }\end{array}$ & Musées nationaux, soutien des DRAC aux musées territoriaux & $\begin{array}{l}\text { Musées municipaux } \\
\text { classés ou contrôlés }\end{array}$ & $\begin{array}{l}\text { Musées } \\
\text { départementaux }\end{array}$ & Intervention possible \\
\hline $\begin{array}{l}\text { Musées } \\
\text { - contrôle }\end{array}$ & $\begin{array}{l}\text { Direction des musées de France, loi du } 22 \text { juillet 1993, loi du } \\
4 \text { janvier } 2002 \text { sur les musées de France, Haut Conseil des } \\
\text { Musées de France }\end{array}$ & & & \\
\hline $\begin{array}{l}\text { Musées } \\
\text { - formation }\end{array}$ & École du Louvre, École nationale du Patrimoine & CNFPT & CNFPT & \\
\hline $\begin{array}{l}\text { Musées } \\
\text { - restauration }\end{array}$ & $\begin{array}{l}\text { Centres de recherche des musées de France, autres centres, } \\
\text { soutiens à l'inventaire et à la numérisation }\end{array}$ & & Intervention possible & Intervention possible \\
\hline $\begin{array}{l}\text { Musées } \\
\text { - éducation }\end{array}$ & Services éducatifs des musées nationaux & $\begin{array}{l}\text { Services éducatifs des } \\
\text { musées municipaux }\end{array}$ & $\begin{array}{l}\text { Services éducatifs } \\
\text { des musées } \\
\text { départementaux }\end{array}$ & $\begin{array}{l}\text { Services éducatifs } \\
\text { des musées régionaux }\end{array}$ \\
\hline $\begin{array}{l}\text { Musées } \\
\text { - associatifs }\end{array}$ & Soutien des DRAC & Intervention possible & Intervention possible & Intervention possible \\
\hline $\begin{array}{l}\text { Musées } \\
\text { - conseil, expertise }\end{array}$ & Conseillers des DRAC & Intervention possible & $\begin{array}{l}\text { Conservations } \\
\text { départementales }\end{array}$ & \\
\hline
\end{tabular}


Tableau 5

Répartition des compétences par domaines en matière de culture - Systèmes d'action sectoriels (suite)

\begin{tabular}{|c|c|c|c|c|}
\hline Domaines & État & Communes & Départements & Régions \\
\hline $\begin{array}{l}\text { Musique et Danse } \\
\text { - enseignement }\end{array}$ & $\begin{array}{l}\text { Établissements publics d'État (Cité de la Musique, } \\
\text { Conservatoires nationaux supérieurs, Lyon et Paris) }\end{array}$ & $\begin{array}{l}\text { CNR, ENM, } \\
\text { Écoles agréées, } \\
\text { écoles municipales, } \\
\text { intercommunales }\end{array}$ & $\begin{array}{l}\text { Écoles } \\
\text { départementales }\end{array}$ & \\
\hline $\begin{array}{l}\text { Musique et Danse } \\
\text { - contrôle, conseil, } \\
\text { réglementation }\end{array}$ & $\begin{array}{l}\text { DMDTS - ministère de la Culture, loi du } 22 \text { juillet } 1983 \\
\text { DRAC, loi du } 10 \text { juillet } 1989\end{array}$ & & & \\
\hline $\begin{array}{l}\text { Musique et Danse } \\
\text { - aide à la création }\end{array}$ & $\begin{array}{l}\text { IRCAM, aide d'État aux organismes, aide à la recherche, } \\
\text { commande publique d'œuvres }\end{array}$ & Intervention possible & Intervention possible & Intervention possible \\
\hline $\begin{array}{l}\text { Musique et Danse } \\
\text { - patrimoine }\end{array}$ & Protection des orgues, CNRS, université & Intervention possible & $\begin{array}{l}\text { Intervention possible } \\
\text { (ADDM) }\end{array}$ & $\begin{array}{l}\text { Intervention possible } \\
\text { (ARDM) }\end{array}$ \\
\hline $\begin{array}{l}\text { Musique et Danse } \\
\text { - diffusion, } \\
\text { pratiques amateurs }\end{array}$ & $\begin{array}{l}\text { Opéras nationaux, centres chorégraphiques nationaux, } \\
\text { co-gestion des ADDM et ARDM }\end{array}$ & $\begin{array}{l}\text { Opéras municipaux, } \\
\text { orchestres, soutiens } \\
\text { aux festivals, } \\
\text { subventions }\end{array}$ & $\begin{array}{l}\text { ADDM, soutien } \\
\text { aux festivals }\end{array}$ & $\begin{array}{l}\text { Orchestres régionaux, } \\
\text { ARDM, soutiens } \\
\text { aux festivals }\end{array}$ \\
\hline $\begin{array}{l}\text { Musique et Danse } \\
\text { - musiques actuelles, } \\
\text { tradititionnelles }\end{array}$ & Aide aux lieux de diffusion & $\begin{array}{l}\text { Scènes de musique } \\
\text { actuelle, traditionnelle }\end{array}$ & Intervention possible & Intervention possible \\
\hline Partenariat Culturel & $\begin{array}{l}\text { Conventions diverses, contrats de ville, CPER..., } \\
\text { Établissement public de coopération culturelle }- \text { loi du } \\
4 \text { janvier } 2002 ; \text { État = partenaire possible des collectivités }\end{array}$ & $\begin{array}{l}\text { Intervention possible, } \\
\text { demande de création }\end{array}$ & $\begin{array}{l}\text { Intervention possible, } \\
\text { demande de création }\end{array}$ & $\begin{array}{l}\text { Intervention possible, } \\
\text { demande de création }\end{array}$ \\
\hline $\begin{array}{l}\text { Patrimoine } \\
\text { - protection }\end{array}$ & $\begin{array}{l}\text { Compétence exclusive sur les procédures de classement } \\
\text { et d'inscription - loi du } 31 \text { décembre } 1913 \\
\text { Cons. rég. du Patrimoine et des Sites (décret } 5 \text { février 1999) } \\
\text { Secteurs sauvegardés, loi du } 4 \text { août } 1962 \\
\text { ZPPAUP loi du } 7 \text { janvier } 1983\end{array}$ & $\begin{array}{l}\text { Garde et conservation } \\
\text { des objets et lieux } \\
\text { de culte, compétence } \\
\text { partagée pour l'insti- } \\
\text { tution d'une ZPPAUP }\end{array}$ & & \\
\hline
\end{tabular}


Tableau 5

Répartition des compétences par domaines en matière de culture - Systèmes d'action sectoriels (suite)

\begin{tabular}{|c|c|c|c|c|}
\hline Domaines & État & Communes & Départements & Régions \\
\hline $\begin{array}{l}\text { Patrimoine } \\
\text { - conservation } \\
\text { et travaux sur } \mathrm{MH}\end{array}$ & $\begin{array}{l}\text { Instruction des travaux par Archit. Bât. de France } \\
\text { Maîtrise d'ouvrage sur monuments classés }\end{array}$ & $\begin{array}{l}\text { Maîtrise d'ouvrage } \\
\text { sur monuments } \\
\text { municipaux } \\
\text { non classés }\end{array}$ & $\begin{array}{l}\text { SDAP, Maîtrise } \\
\text { d'ouvrage sur } \\
\text { monuments départe- } \\
\text { mentaux non classés }\end{array}$ & Intervention possible \\
\hline $\begin{array}{l}\text { Patrimoine } \\
\text { - patrimoine } \\
\text { non protégé }\end{array}$ & $\begin{array}{l}\text { Fondation du Patrimoine } \\
\text { Soutien des DRAC }\end{array}$ & Intervention possible & Intervention possible & Intervention possible \\
\hline $\begin{array}{l}\text { Patrimoine } \\
\text { - gestion des } \\
\text { monuments d'État }\end{array}$ & Centre des monuments nationaux & & & \\
\hline $\begin{array}{l}\text { Patrimoine } \\
\text { - inventaire des } \\
\text { richesses patrimon. }\end{array}$ & $\begin{array}{l}\text { Méthodologie, inventaire général, DAPA, conservations } \\
\text { régionales DRAC }\end{array}$ & Services municipaux & $\begin{array}{l}\text { Services } \\
\text { départementaux }\end{array}$ & Intervention possible \\
\hline $\begin{array}{l}\text { Patrimoine } \\
\text { - archéologie }\end{array}$ & $\begin{array}{l}\text { Loi validée du } 27 \text { décembre 1941, loi du } 17 \text { janvier } 2001 \\
\text { Fouilles, base de données, CNRS, université }\end{array}$ & Intervention possible & Intervention possible & Intervention possible \\
\hline $\begin{array}{l}\text { Patrimoine } \\
\text { - ethnologique }\end{array}$ & $\begin{array}{l}\text { Mission du patrimoine ethnologique (DAPA), } \\
\text { Conseillers DRAC, CNRS et université }\end{array}$ & Intervention possible & Intervention possible & Intervention possible \\
\hline $\begin{array}{l}\text { Patrimoine } \\
\text { - contrôle }\end{array}$ & Inspection générale du Patrimoine, DRAC & & & \\
\hline $\begin{array}{l}\text { Patrimoine } \\
\text { - formation }\end{array}$ & $\begin{array}{l}\text { Centre des Hautes Études de Chaillot, École nationale du } \\
\text { Patrimoine, Institut français de restauration d'œuvres d'art }\end{array}$ & & & \\
\hline $\begin{array}{l}\text { Patrimoine } \\
\text { - recherche }\end{array}$ & Laboratoire de recherche sur les $\mathrm{MH}$ et autres centres & Intervention possible & Intervention possible & Intervention possible \\
\hline
\end{tabular}


Tableau 5

Répartition des compétences par domaines en matière de culture - Systèmes d'action sectoriels (suite)

\begin{tabular}{|c|c|c|c|c|}
\hline Domaines & État & Communes & Départements & Régions \\
\hline $\begin{array}{l}\text { Patrimoine } \\
\text { - connaissance, } \\
\text { action culturelle }\end{array}$ & $\begin{array}{l}\text { Monuments appartenant à l'État, centres culturels } \\
\text { de rencontre, musées nationaux (archéologie, histoire, } \\
\text { ethnographie), publications, label VPAH }\end{array}$ & $\begin{array}{l}\text { Monuments et musées } \\
\text { municipaux, publica- } \\
\text { tions, expositions, } \\
\text { VPAH }\end{array}$ & $\begin{array}{l}\text { Monuments et musées } \\
\text { départementaux }\end{array}$ & Intervention possible \\
\hline $\begin{array}{l}\text { Patrimoine } \\
\text { - conseil, expertise }\end{array}$ & Services patrimoniaux DRAC & $\begin{array}{l}\text { Intervention possible } \\
\text { (services patrimoniaux, } \\
\text { archéologiques) }\end{array}$ & $\begin{array}{l}\text { Intervention possible } \\
\text { (services patrimoniaux, } \\
\text { archéologiques) }\end{array}$ & $\begin{array}{l}\text { Intervention possible } \\
\text { (services patrimoniaux, } \\
\text { archéologiques) }\end{array}$ \\
\hline $\begin{array}{l}\text { Théâtre, Spectacles } \\
\text { - réglementation }\end{array}$ & Loi du 18 mars 1999, licence accordée par les DRAC & & & \\
\hline $\begin{array}{l}\text { Thêâtre, Spectacles } \\
\text { - création, diffusion }\end{array}$ & $\begin{array}{l}\text { Théâtres nationaux, centres dramatiques nationaux, } \\
\text { scènes nationales, ONDA }\end{array}$ & $\begin{array}{l}\text { Théâtres municipaux, } \\
\text { scènes nationales, } \\
\text { aides aux lieux } \\
\text { de création-diffusion }\end{array}$ & $\begin{array}{l}\text { Aides aux lieux } \\
\text { de création-diffusion }\end{array}$ & $\begin{array}{l}\text { Aides aux lieux } \\
\text { de création-diffusion }\end{array}$ \\
\hline $\begin{array}{l}\text { Théâtre, Spectacles } \\
\text { - aides aux } \\
\text { compagnies }\end{array}$ & Aides DRAC - Compagnies professionnelles & $\begin{array}{l}\text { Intervention possible } \\
\text { (aides aux } \\
\text { compagnies) }\end{array}$ & $\begin{array}{l}\text { Intervention possible } \\
\text { (aides aux } \\
\text { compagnies) }\end{array}$ & $\begin{array}{l}\text { Intervention possible } \\
\text { (aides aux } \\
\text { compagnies) }\end{array}$ \\
\hline $\begin{array}{l}\text { Théâtre, Spectacles } \\
\text { - aide à l'écriture }\end{array}$ & Aide DMDTS aux écritures contemporaines & Intervention possible & Intervention possible & Intervention possible \\
\hline $\begin{array}{l}\text { Théâtre, Spectacles } \\
\text { - pratique amateur }\end{array}$ & Classes Théâtre A3 Lycées & $\begin{array}{l}\text { Conservatoire et écoles } \\
\text { d'art, associations }\end{array}$ & $\begin{array}{l}\text { Écoles d'art, } \\
\text { associations }\end{array}$ & Intervention possible \\
\hline $\begin{array}{l}\text { Théâtre, Spectacles } \\
\text { - conseil, expertise }\end{array}$ & Conseillers Théâtre, DRAC & & & \\
\hline
\end{tabular}


- Les fonctions qui, au contraire, manifestent le plus de partenariat ou d'intervention parallèles sont les suivantes : aide, développement, pratiques, diffusion, éducation, association, commande publique, établissements.

- Des trois niveaux de collectivité territoriale, c'est le niveau régional qui manifeste la présence la plus inégale, la moins institutionnalisée et la plus variable au gré des volontés politiques. C'est à l'inverse la commune qui manifeste la plus grande fréquence sur l'ensemble des domaines.

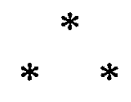

Au terme de cet état des lieux des politiques culturelles et de la répartition des compétences, trois rappels s'imposent :

- Il faut tenir compte des trois dimensions centrales des politiques culturelles : le rôle particulier conféré à l'État depuis plus de quarante ans d'institutionnalisation de ces politiques ; le partenariat État-collectivités qui en est le mode cardinal d'effectuation; la pluralité des niveaux d'action fondée sur un principe dominant de liberté d'intervention.

- Penser la décentralisation exige de penser en même temps l'évolution des missions qui incombent à l'État, et la recomposition de sa propre intervention. La définition en creux, comme on le voit actuellement se dessiner, d'un État simplement délesté de certains domaines, en faisant l'économie d'une réflexion sur sa place dans la «gouvernance territoriale », nous paraît mener à une impassc, au moins dans le domaine culturel. Toute réflexion sur la décentralisation conduit ainsi à penser simultanément la déconcentration qui constitue presque, à l'échelle européenne, une exception culturelle.

- La politique culturelle, quel que soit son niveau d'exercice et en dépit de sa forte institutionnalisation, consiste le plus souvent dans la réponse, par la puissance publique, à des initiatives, des projets et des besoins exprimés par des professionnels, des associations, des publics. Même si la notion de service public, en matière de culture, ne constitue juridiquement qu'un cadre limité, l'intervention de cette politique s'appuie sur la construction symbolique d'un intérêt général apte à fonder le soutien à de telles initiatives, en contribuant au besoin à leur formulation, à leur orientation, à leur prise en charge directe. Cette construction « symbolique » permet de qualifier et de disqualifier acteurs et champs selon des logiques évolutives et structurellement contestables.

Parallèlement aux débats en cours sur l'architecture des politiques publiques, se déroulent d'autres débats sur son domaine, et sur son contenu, dont la nature juridique est encore plus relative, mais dont l'importance politique et sociale s'avère grandissante. Quant au domaine, il s'agit notamment de l'étroitesse des marges de manœuvre de législations purement nationales (voire européenne) pour entretenir un régime d'exception culturelle, qui le tienne simultanément à distance des règles de concurrence et des tentations d'instrumentalisation politique. Or ce régime, à 
l'échelle internationale, n'a été que provisoirement préservé, et les échéances se rapprochent d'une renégociation des droits particuliers qui s'appliquent à l'univers des politiques culturelles. Cette renégociation se profile dans un contexte où le contenu de ces politiques fait l'objet de nouvelles discussions. Après les déceptions statistiques des années 80 sur les pratiques culturelles et les pamphlets des années 90 sur le contenu des politiques de l'État, un certain désenchantement intellectuel vise désormais la culture en tant que telle $\mathrm{e}^{25}$, quand de nouveaux foyers de création travaillent, quotidiennement, à son réenchantement par la pratique. Autant de sources de pressions qui marqueront à leur manière la mise en cuvre d'un nouveau cadre institutionnel comme il contribue, dès aujourd'hui, à débattre de l'actuel.

25. Voir la revue Esprit, « Quelle culture défendre ? », Paris, mars-avril 2002. 